Original article

\title{
3-(4-Hydroxyphenyl)propionic acid is involved in the biosynthesis of myricanol in Myrica
}

\section{5 rubra}

Shingo Kawai, Kyousuke Nakata, Hiroo Ichizawa, Tomoaki Nishida

Shingo Kawai $(\bowtie) \cdot$ Kyousuke Nakata $・$ Hiroo Ichizawa $・$ Tomoaki Nishida

10 Laboratory of Forest Microbiology and Biochemistry,

Department of Environment and Forest Resources Science,

Faculty of Agriculture, Shizuoka University

Ohya, Suruga-ku, Shizuoka 422-8529, JAPAN

15 Tel. +81-54-238-4851; Fax +81-54-238-4851

E-mail: skawai@agr.shizuoka.ac.jp

Keyword: Myrica rubra; Cyclic diarylheptanoids; Myricanol; Biosynthesis;

20 3-(4-Hydroxyphenyl)propionic acid; 4-Coumaric acid; ${ }^{13} \mathrm{C}-\mathrm{NMR}$

Part of this report was presented at the 52nd Lignin symposium, Utsunomiya, 25 November 2007. 


\begin{abstract}
There is little evidence about the biosynthetic pathways for cyclic diarylheptanoids. We previously demonstrated that the cyclic diarylheptanoids, myricanol and myricanone, were biologically synthesized from two molecules of

5 4-coumaric acid by the feeding $4-\left[8,9-{ }^{13} \mathrm{C}_{2}\right]$ coumaric acid to young shoot of Myrica rubra.
\end{abstract}

In the present study, using a ${ }^{13} \mathrm{C}$-labeled compound, we revealed that two molecules of 3-(4-hydroxyphenyl)propionic acid could also be a biosynthetic precursor of myricanol in M. rubra. These results indicated that both 4-coumaric

10 acid and its dihydro-derivative were incorporated into myricanol. Competitive feeding experiments with $4-\left[8,9-{ }^{13} \mathrm{C}_{2}\right]$ coumaric acid and 3-(4-hydroxyphenyl)-[ $\left[1-{ }^{13}\right.$ C]propionic acid were performed in M. rubra to determine the preferential incorporation of these two precursors. ${ }^{13} \mathrm{C}-\mathrm{NMR}$ studies indicated that 3-(4-hydroxyphenyl)-[1- $\left.{ }^{13} \mathrm{C}\right]$ propionic acid was preferentially

15 incorporated into myricanol. The data provided evidence for a biosynthetic sequence originating from 4-coumaric acid and leading to myricanol, through 3-(4-hydroxyphenyl)propionic acid in M. rubra. 


\section{Introduction}

Cyclic diarylheptanoids, myricanol (I) and myricanone (II), are two of the major components in Myrica rubra Sieb. et Zucc., ${ }^{1,2}$ and are reported to have antitumor-promoting effects ${ }^{3}$ and exhibit anti-androgen activities. ${ }^{4}$ The bark of

5 M. rubra was also used as an astringent, antidote and antidiarrheal in Japanese folk medicine and has been used externally for burn and skin diseases in Chinese traditional medicine.

Diarylheptanoids comprise a class of natural products based on 1,7-diphenylheptane and have been isolated from Myricaceae, Betulaceae,

10 Zingiberaceae, and Aceraceae plants. ${ }^{5.6}$ The biosynthesis of diarylheptanoids, especially phenylphenalenone derivatives, ${ }^{7-11}$ has been investigated and two molecules of 4-coumaroyl-CoA and one malonyl-CoA are reported to be concerned with the formation of their skeleton. However, there is little knowledge about the biosynthetic pathways for cyclic diarylheptanoids.

Our recent report on $M$. rubra young shoots fed with 4- $\left[8,9-{ }^{13} \mathrm{C}_{2}\right]$ coumaric acid $\left(\left[\mathbf{8 , 9 - 9}-{ }^{\mathbf{1 3}} \mathbf{C}_{2}\right]-\mathbf{I I I}\right)$ revealed, through mass and ${ }^{13} \mathrm{C}-\mathrm{NMR}$ spectrometric analyses, that myricanol (I) and myricanone (II) were derived from two molecules of 4-coumaric acid (III). ${ }^{12}$ In particular, the ${ }^{13} \mathrm{C}-\mathrm{NMR}$ analyses of myricanol (I) isolated after administration of $4-\left[8,9-{ }^{13} \mathrm{C}_{2}\right]$ coumaric acid

$20\left(\left[\mathbf{8 , 9 -}{ }^{13} \mathbf{C}_{2}\right]-\right.$ III $)$ clearly demonstrated that C-8, C-9, C-11, and C-12 of myricanol (I) were derived from the C-8 and C-9 atoms of 4-coumaric acid (III). However, in a comparison of the chemical structures of myricanol (I) and 4-coumaric acid (III), the chain structures were apparently different, i.e. myricanol (I) had no unsaturated bond in the molecule. Therefore, it is conceivable that 
dihydro-analog for 4-coumaric acid (III), could be a biosynthetic precursor for myricanol (I).

In this paper, we reported on whether 3-(4-hydroxyphenyl)propionic acid (IV) was incorporated into myricanol (I). Furthermore, competitive feeding

5 experiments on $M$. rubra with ${ }^{13} \mathrm{C}$ lebelled precursors of 4-coumaric acid (III) and 3-(4-hydroxyphenyl)propionic acid (IV) were conducted. Biosynthetic ${ }^{13} \mathrm{C}-\mathrm{NMR}$ studies indicated that 3-(4-hydroxyphenyl)propionic acid (IV) was preferentially employed in the formation of myricanol (I) in M. rubra. 


\section{Materials and Methods}

General

Analytical and preparative TLCs were performed on silica gel (Merck Kieselgel $\left.60 \mathrm{~F}_{254}\right) .{ }^{1} \mathrm{H}$ and ${ }^{13} \mathrm{C}-\mathrm{NMR}$ spectra were taken with JEOL JMM EX-270

5 spectrometer using tetramethylsilane as an internal standard. EI-MS analyses were performed with a Shimadzu GCMS-QP 5050 gas chromatograph mass spectrometer.

Syntheses of labeled precursors and authentic compounds

The chemical structures of $4-\left[8,9-{ }^{13} \mathrm{C}_{2}\right]$ coumaric acid $\left(\left[\mathbf{8 , 9 - 9}{ }^{\mathbf{1 3}} \mathrm{C}_{2}\right]-\mathbf{I I I}\right)$ and 3-(4-Hydroxyphenyl)- $\left[1-{ }^{13} \mathrm{C}\right]$ propionic acid $\left(\left[\mathbf{1 -}{ }^{\mathbf{1 3}} \mathbf{C}\right]-\mathbf{I V}\right)$ were illustrated in Fig.1.

3-(4-Hydroxyphenyl)-[1- $\left.{ }^{13} \mathrm{C}\right]$ propionic acid $\left(\left[\mathbf{1 -}{ }^{\mathbf{1 3}} \mathbf{C}\right]-\mathbf{I V}\right)$ was synthesized from $\left[9-{ }^{13} \mathrm{C}\right]$ coumaric acid $\left(\left[\mathbf{9 -}{ }^{13} \mathbf{C}\right]-\mathbf{I I I}\right)$ prepared from

15 4-acetoxybenzaldehyde and $\left[1-{ }^{13} \mathrm{C}\right]$ triethyl phosphonoacetate (Aldrich, 99 atom\% $\left.{ }^{13} \mathrm{C}\right)$ by the method of previously described. ${ }^{12}$

To a solution of $\left[9-{ }^{13} \mathrm{C}\right]$ coumaric acid $\left(\left[\mathbf{9 -}{ }^{\mathbf{1 3}} \mathbf{C}\right]-\mathbf{I I I}\right)(59.4 \mathrm{mg}, 0.36$ mmol $)$ in methanol $(2 \mathrm{ml})$ and acetic acid $(0.1 \mathrm{ml}), 10 \%$ palladium carbon $(100$ mg, Wako) was added, and the flask was evacuated and then filled with hydrogen

20 gas. The resulting solution was stirred at ambient temperature for $60 \mathrm{~min}$. The reaction mixture was filtered off, and washed with methanol. The filtrate was evaporated under reduced pressure, and the residue was purified by TLC (solvent: $\left.\mathrm{MeOH}-\mathrm{CHCl}_{3}, 5 / 95\right)$ to give 3-(4-hydroxyphenyl)- $\left[1-{ }^{13} \mathrm{C}\right]$ propionic acid $\left(\left[1-{ }^{13} \mathrm{C}\right]-\mathbf{I V}\right)(38.0 \mathrm{mg}, 63 \%)$. 


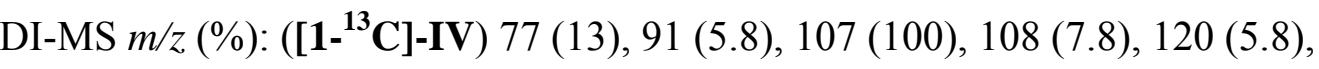
166 (0.0), 167 (28), 168 (2.7), 169 (0.3); (IV) 77 (16), 91 (6.6), 107 (100), 108 (7.6), 120 (6.2), $166\left(\mathrm{M}^{+}, 23\right), 167(2.4), 168(0.2), 169(0.0)$.

${ }^{13} \mathrm{C}-\mathrm{NMR}\left(\mathrm{CD}_{3} \mathrm{OD}, 67.5 \mathrm{~Hz}\right) \delta:\left(\left[\mathbf{1}-{ }^{13} \mathbf{C}\right]-\mathbf{I V}\right) 176.9$ (C-1); (IV) 31.2 (C-3), 37.6

$5 \quad$ (C-2), 115.6 (C-8), 116.2 (C-3’, C-5'), 130.2 (C-2’', C-6'), 132.9 (C-1'), 156.7 (4'-C), $176.9(\mathrm{C}-1)$.

4-[8,9- $\left.{ }^{13} \mathrm{C}_{2}\right]$ Coumaric acid $\left(\left[\mathbf{8 , 9 - 9}{ }^{\mathbf{1 3}} \mathrm{C}_{2}\right]\right.$-III) was prepared as described previously. ${ }^{12}$ Authentic myricanol (I) and myricanone (II) were previously isolated from the branches of M. rubura. ${ }^{12}$

Feeding experiment with 3-(4-hydroxyphenyl)- $\left[1-{ }^{13} \mathrm{C}\right]$ propionic acid $\left(\left[\mathbf{1 -}{ }^{\mathbf{1 3}} \mathbf{C}\right]-\mathbf{I V}\right)$ 3-(4-Hydroxyphenyl)-[1- $\left.{ }^{13} \mathrm{C}\right]$ propionic acid ([1- $\left.\left.{ }^{\mathbf{1 3}} \mathbf{C}\right]-\mathbf{I V}\right)(4.2 \mathrm{mg}(25$ $\mu \mathrm{mol}$ ) in $1 \mathrm{ml}$ of $0.1 \% \mathrm{NaOH}$ ) was administrated to excised $M$. rubra young shoots (harvested on October, 2006, shoot size: 20-30 cm), which were allowed to

15 metabolize for 2 weeks at room temperature under continuous light. The feeding experiments were duplicated. After incubation, the leaves were removed from the resulting shoots, and stems were frozen, powdered with a pestle and mortar, and extracted with hot $\mathrm{MeOH}$ for $12 \mathrm{hr}$. The extracts were partitioned between EtOAc and water. The organic layer was washed with brine, dried over anhydrous

$20 \mathrm{Na}_{2} \mathrm{SO}_{4}$, and evaporated under reduced pressure. The myricanol (I) and myricanone (II) fractions were roughly separated from the extracts by TLC (solvent: ethyl acetate/n-hexane, 1/2), respectively, and analyzed by GC-MS. Then, the myricanol (I) and myricanone (II) fractions were combined, respectively, and further purified by TLC (solvent: $\mathrm{MeOH}-\mathrm{CHCl}_{3}, 2 / 95$ ). The 25 purified myricanol (I) $(\sim 3 \mathrm{mg})$ and myricanone $($ II $)(<1 \mathrm{mg})$ were analyzed by 
selected ion monitoring (SIM) of DI-MS, respectively. ${ }^{13} \mathrm{C}-\mathrm{NMR}$ analysis of the myricanol (I) was also performed.

Competitive feeding experiment with $4-\left[8,9-{ }^{13} \mathrm{C}_{2}\right]$ coumaric acid $\left(\left[\mathbf{8 , 9 - 9}{ }^{\mathbf{1 3}} \mathbf{C}_{2}\right]-\mathbf{I I I}\right)$

5 and 3-(4-hydroxyphenyl)-[1- $\left.{ }^{13} \mathrm{C}\right]$ propionic acid ([1- $\left.\left.{ }^{13} \mathbf{C}\right]-\mathbf{I V}\right)$

Equal amount of $4-\left[8,9-{ }^{13} \mathrm{C}_{2}\right]$ coumaric acid $\left(\left[\mathbf{8 , 9 - 9}{ }^{13} \mathbf{C}_{2}\right]-\mathbf{I I I}\right)(2.1 \mathrm{mg}$, $12.5 \mu \mathrm{mol})$ and 3-(4-hydroxyphenyl)-[1- $\left.{ }^{13} \mathrm{C}\right]$ propionic acid $\left(\left[\mathbf{1 -}{ }^{13} \mathbf{C}\right]-\mathbf{I V}\right)(2.1 \mathrm{mg}$, $12.5 \mu \mathrm{mol}$ ) was combined and dissolved in $1 \mathrm{ml}$ of $0.1 \% \mathrm{NaOH}$ solution. The mixed solution was administrated to excised $M$. rubura young shoots (harvested 10 on October, 2006 and 2007, shoot size: $20-30 \mathrm{~cm}$ ), which were allowed to metabolize for 2 weeks at room temperature under continuous light. . The feeding experiments were duplicated. After incubation, the myricanol (I) and myricanone (II) fractions were separated and analyzed as mentioned above. 


\section{Results and Discussion}

3-(4-Hydroxyphenyl)-[1- $\left.{ }^{13} \mathrm{C}\right]$ propionic acid $([\mathbf{1 - 1 3} \mathbf{C}]-\mathbf{I V})$ was

administered to excised $M$. rubra young shoots, and it was allowed to metabolize for 2 weeks. The myricanol (I) and myricanone (II) fractions, obtained by TLC

5 separation, were analyzed by GC-MS (data not shown), respectively, and the formation of $\left[{ }^{13} \mathrm{C}_{2}\right]$-myricanol (I) and $\left[{ }^{13} \mathrm{C}_{2}\right]$-myricanone (II) were determined by comparison with unlabeled authentic compounds. These fractions were further purified by TLC to confirm the incorporation rate of ${ }^{13} \mathrm{C}$ carbon into myricanol (I) (Fig. 2B) and myricanone (II) (Fig. 2E) using DI-MS with SIM mode. As shown

10 in Table 1, the results indicated that ca. $3 \%$ of myricanol (I) and ca. $3 \%$ of myricanone (II) were biosynthesized from two molecules of 3-(4-hydroxyphenyl)-[1- $\left.{ }^{13} \mathrm{C}\right]$ propionic acid $\left(\left[\mathbf{1 -}{ }^{13} \mathbf{C}\right]-\mathbf{I V}\right)$, respectively.

${ }^{13} \mathrm{C}-\mathrm{NMR}$ analysis of myricanol (I) was conducted to determine the ${ }^{13} \mathrm{C}$-enriched position in the heptane-chains (Fig. 3). The NMR spectra of the

15 isolated myricanol (I) after administration of 3-(4-hydroxyphenyl)-[1- $\left.{ }^{13} \mathrm{C}\right]$ propionic acid $\left(\left[\mathbf{1 -}{ }^{\mathbf{1 3}} \mathbf{C}\right]-\mathbf{I V}\right)$ (Fig. $3 B$ ) displayed enhancements of ${ }^{13} \mathrm{C}$ resonances at C-9 $(\delta$ 22.9) and C-11 ( $\delta$ 68.6) positions. The magnified figures of each heptane-chain carbon $(\mathrm{C}-7-\mathrm{C}-13)$ in the ${ }^{13} \mathrm{C}-\mathrm{NMR}$ spectra of myricanol (I) are illustrated in Fig. 4, and the relative integral

20 intensities of the heptane-chain carbons, based on that of C-10, were calculated as shown in Table 2. The relative intensities of the ${ }^{13} \mathrm{C}$-signals were enhanced 3.6 and 3.2 times [i.e. Intensity of singlet peak / Intensity of naturally occurring singlet peak] for C-9 and C-11, respectively (Fig. 4B). These results clearly indicated that two molecules of 3-(4-hydroxyphenyl)- $\left[1-{ }^{13} \mathrm{C}\right]$ propionic acid

25 ([1- $\left.\left.{ }^{13} \mathbf{C}\right]-\mathbf{I V}\right)$ were incorporated into myricanol (I). 
We have recently reported that two molecules of 4-coumaric acid (III) were precursors of myricanol (I) and myricanone (II) in M. rubra. ${ }^{12}$ In extending our feeding experiments, we have obtained more detailed data indicating that 3-(4-hydroxyphenyl)propionic acid (IV) also behaves as an intermediate. The

5 heptane-chain of myricanol (I) is saturated, whereas 4-coumaric acid (IV) has an unsaturated propane-chain. Therefore, it is conceivable that 3-(4-hydroxyphenyl)propionic acid (IV), which is the dihydro-analog for 4-coumaric acid (III), could be biosynthetic precursor for myricanol (I).

A competitive feeding experiment was conducted with two ${ }^{13} \mathrm{Cs}$ labeled

10 4-coumaric acid $\left(\left[\mathbf{8 , 9 - 9}{ }^{13} \mathbf{C}_{2}\right]-\right.$ III $)$ and single ${ }^{13} \mathrm{C}$ labeled 3-(4-hydroxyphenyl)propionic acid $\left(\left[\mathbf{1 -}{ }^{\mathbf{1 3}} \mathbf{C}\right]-\mathbf{I V}\right)$ to examine which is the downstream of metabolism precursor for myricanol biosynthesis. The myricanol (I) and myricanone (II) fractions were purified and analyzed by DI-MS (Fig. 2C and $2 F$ ). As shown in Table 1, the results proved that ${ }^{13} \mathrm{C}$ derived from labeled

15 precursor(s) was incorporated into both myricanol (I) and myricanone (II), but the results could not determine which precursors, $\left(\left[\mathbf{8 , 9 -}{ }^{\mathbf{1 3}} \mathbf{C}_{2}\right]-\mathbf{I I I}\right)$ or $\left(\left[\mathbf{1 -}{ }^{\mathbf{1 3}} \mathrm{C}\right]-\mathbf{I V}\right)$, was preferentially incorporated into (I) and (II). Consequently, the ${ }^{13} \mathrm{C}-\mathrm{NMR}$ spectrum of myricanol (I) formed by this feeding experiment was measured (Fig. 3C).

If 4-[8,9- $\left.{ }^{13} \mathrm{C}_{2}\right]$ coumaric acid $\left(\left[\mathbf{8 , 9 - 9}{ }^{\mathbf{1 3}} \mathbf{C}_{2}\right]-\right.$ III $)$ was incorporated into

20 myricanol (I), the resonances of C-8 ( $\delta$ 25.7), C-9 ( $\delta$ 22.9), C-11 ( $\delta$ 68.6), and C-12 ( $\delta 34.7)$ would appear as pseudo-triplets, thus indicating the presence of naturally occurring isotopomers (a singlet, central resonances of the pseudo-triplets) and isotopomers derived from two labeled carbons of 4- $\left[8,9-{ }^{13} \mathrm{C}_{2}\right]$ coumaric acid $\left(\left[\mathbf{8 , 9 - 9}{ }^{13} \mathbf{C}_{2}\right]-\mathbf{I I I}\right)$ in these positions (a doublet, due to $25{ }^{13} \mathrm{C}-{ }^{13} \mathrm{C}$ couplng with adjacent $\left.{ }^{13} \mathrm{C}\right)$. However, if 3-(4-hydroxyphenyl)-[1- $\left.{ }^{13} \mathrm{C}\right]$ propionic acid $\left(\left[\mathbf{1 -}{ }^{\mathbf{1 3}} \mathbf{C}\right]-\mathbf{I V}\right)$ was incorporated, the 
singlet resonances of C-9 and C-11 would be stronger than the signals of naturally occurring isotopomers.

As shown in Fig. $4 C$, the ${ }^{13}$ C-NMR spectrum of myricanol (I) isolated after administration of ${ }^{13} \mathrm{C}$ labeled 4-coumaric acid $\left(\left[\mathbf{8 , 9 -}{ }^{13} \mathbf{C}_{2}\right]-\right.$ III $)$ and

5 3-(4-hydroxyphenyl)propionic acid $\left(\left[\mathbf{1}-{ }^{13} \mathbf{C}\right]-\mathbf{I V}\right)$ is very complex. As the C-9 and C-11 singlet signals were enhanced, it is clear that two molecules of 3-(4-hydroxyphenyl)-[1- $\left.{ }^{13} \mathrm{C}\right]$ propionic acid $\left(\left[\mathbf{1}-{ }^{\mathbf{1 3}} \mathbf{C}\right]-\mathbf{I V}\right)$ were incorporated into myricanol (I). On the other hand, doublet signals were also detected at C-8, C-9, C-11, and C-12; thus, incorporation of two molecules of $4-\left[8,9-{ }^{13} \mathrm{C}_{2}\right]$ coumaric

10 acid ([8,9- $\left.\left.{ }^{\mathbf{1 3}} \mathbf{C}_{2}\right]-\mathbf{I I I}\right)$ to myricanol (I) was also confirmed. However, the incorporation ratios were different. In comparison with doublet signals of C-9 and C-11, the stronger singlet signals of C-9 and C-11 revealed a higher degree of incorporation of 3-(4-hydroxyphenyl)-[1- $\left.{ }^{13} \mathrm{C}\right]$ propionic acid $\left(\left[\mathbf{1 -}{ }^{\mathbf{1 3}} \mathbf{C}\right]-\mathbf{I V}\right)$ compared to $4-\left[8,9-{ }^{13} \mathrm{C}_{2}\right]$ coumaric acid $\left(\left[\mathbf{8 , 9 -}-{ }^{\mathbf{1 3}} \mathbf{C}_{2}\right]-\mathbf{I I I}\right)$. Based on the intensities of 15 doublets [i.e., Sum of doublet intensities] and singlets [i.e., Intensity of singlet peak - Intensity of naturally occurring singlet] (Table 2), the incorporation ratios of labeled precursors $\left(\left[\mathbf{8 , 9 - 9}-{ }^{13} \mathbf{C}_{2}\right]-\mathbf{I I I}\right)$ and $\left(\left[\mathbf{1 -}{ }^{\mathbf{1 3}} \mathbf{C}\right]-\mathbf{I V}\right)$ were estimated to be $c a .1$ : 1.6 for C-9 [doublet (2.09) : singlet $(3.27 ; 4.28-1.01)$ ] and ca. $1: 8.4$ for C-11 [doublet (0.46): singlet $(3.87 ; 4.98-1.11)$ ], respectively. In our present studies, 3-(4-hydrixyphenyl)propionic acid (IV) could be biosynthetic precursor of myricanol (I) and preferentially incorporated into myricanol (I) rather than 4-coumaric acid (III). Under in vivo conditions used in this study, multiple factors, such as solubility of the precursors, their absorption by the plant and so on, are affecting incorporation of precursors. However, when $254-\left[8,9-{ }^{13} \mathrm{C}_{2}\right]$ coumaric acid $\left(\left[\mathbf{8 , 9 - 9}{ }^{13} \mathrm{C}_{2}\right]-\right.$ III $)$ or 3-(4-hydroxyphenyl)- $\left[1-{ }^{13} \mathrm{C}\right]$ propionic acid $\left(\left[\mathbf{1 -}{ }^{\mathbf{1 3}} \mathbf{C}\right]-\mathbf{I V}\right)$ was administered alone 
into M. rubra, the incorporation rate of them into myricanol (I) were relatively similar $(3-6 \%)$. Therefore, the present results suggest that direct incorporation of dihydro-phenylpropanoid-type precursors into myricanol (I) and the dehydrogenation of a side chain of 4-coumaric acid (III) occurs prior to the

5 formation of a diarylheptanoid skeleton (Fig. 5).

Similar results were reported by Kindl and coworkers ${ }^{13,14}$ regarding the biosynthesis of 9,10-dihydrophenanthrenes (stilbenoids) of Orchidaceae. They demonstrated that 3-(3-hydroxyphenyl)propionic acid, as a dihydro-phenylpropanoid precursor, was incorporated into orchinol, and that $103,3^{\prime}, 5$-trihydroxybibenzyl, obtained through the operation of bibenzyl synthase, and not stilbene synthase, was an intermediate compound of 9,10-dihydrophenanthrenes. However, the possibility of the interconversion between 4-coumaric acid (III) and 3-(4-hydroxyphneyl)propionic acid (IV) ${ }^{15}$ in M. rubra remains to be investigated. In the biosynthesis of diarylheptanoids, the involvement with chalcone synthase-related type III plant polyketide synthase (PKS III) was presumed. ${ }^{16}$ Brand et al. ${ }^{17}$ reported a new PKS III gene cloned from Wachendorfia thyrsiflora, and the enzyme catalyzed the formation of a diketide, which is considered as a biosynthetic intermediate of phenylphenalenone derivatives. Furthermore,

20 Ramirez-Ahumada et al. ${ }^{18}$ detected the activity of curcuminoid synthase in turmeric, which required both 4-coumaroyl-CoA esters and malonyl-CoA for curcuminoid biosynthesis. Katsuyama et al. ${ }^{19}$ recently demonstrated the in vitro synthesis of curcuminoids by PKS III from Oryza sativa. Therefore, a similar PKS III might be involved in the biosynthesis of myricanol derivatives in M. rubra.

25 However, in the case of myricanol (I), it is likely that another diphenylheptane 
synthase, which uses a dihydro-phenylpropanoid precursor as a substrate, could be involved.

Furthermore, the findings that the incorporation ratios of 4- $\left[8,9-{ }^{13} \mathrm{C}_{2}\right]$ coumaric acid $\left(\left[\mathbf{8 , 9 - 9}{ }^{13} \mathrm{C}_{2}\right]-\right.$ III $)$ and

5 3-(4-hydroxyphenyl)-[1- $\left.{ }^{13} \mathrm{C}\right]$ propionic acid ([1- $\left.\left.{ }^{13} \mathrm{C}\right]-\mathbf{I V}\right)$ differ between C-9 (1 : 1.6) and C-11 (1 : 8.4) in myricanol (I) is an interesting result. Myricanol (I) has two different types of aromatic rings; the A-ring has two methoxyl and one phenolic hydroxyl groups, whereas the B-ring has only one phenolic hydroxyl group. If the diarylheptanoid skeleton is built from two same precursors, for

10 example 3-(4-hydroxyphenyl)propionyl-CoA, the incorporation ratios at C-9 and C-11 may be indistinguishable due to symmetry. These results strongly suggest that hydroxylation (and/or methylation) of A-ring may occurs before building of diarylheptanoid skelton. We are presently attempting to determine whether ${ }^{13} \mathrm{C}$-labeled caffeic acid, ferulic acid, dihydro-caffeic acid and/or dihydro-ferulic 15 acid are incorporated into myricanol (I). 
Acknowledgement The authors wish to thank Akihito Yagi, Technical Support

Division, Faculty of Agriculture, Shizuoka University, for assistance with NMR analyses. 


\section{References}

1. Begley, M. J., Campbell, R. V. M., Crombie, L., Tuck, B., Whiting, D. A., 1971. Constitution and absolute configuration of meta,meta-bridged, strained biphenyls from Myrica nagi; X-ray analysis of 16-bromomyricanol. J. Chem. Soc. (C), 3634-3642.

2. Sakurai, N., Yaguchi, Y., Tetsuro Hirakawa, T., Nagaia, M., Inoue, T., 1991. Two myricanol glycosides from Myrica rubra and revision of the structure of isomyricanone. Phytochemistry 30, 3077-3079.

3. Ishida, J., Kozuka, M., Wang, H. K., Konoshima, T., Tokuda, H., Okuda, M., Mou, X. Y., Nishino, H,, Sakurai, N., Lee, K. H., Nagai, M., 2000. Antitumor-promoting effects of cyclic diarylheptanoids on Epstein-Barr virus activation and two-stage mouse skin carcinogenesis. Cancer Lett. 159, 135-140.

4. Matsuda, H., Yamazaki, M., Matsuo, K., Asanuma, Y., Kubo, M., 2001. Anti-androgenic activity of Myricae Cortex - Isolation for active constituents from bark of Myrica rubra. Biol. Pharm. Bull. 24, 259-263.

5. Norin, T., 1989. Stilbens, Conioids and Other Polyaryl Natural Products. In: Rowe, J. W. (Ed.) Natural Products of Woody Plants I. Springer-Verlag, Berlin, pp. 512-533.

20 6. Inoue, T., 1993. Constituents of Acer nikoense and Myrica rubra. On diarylheptanoids (in Japanese). Yakugaku Zasshi 113, 181-197.

7. Hölscher, D., Schneider, B., 1995. A diarylheptanoid intermediate in the biosynthesis of phenylphenalenones in Anigozanthos preissi. J. Chem. Soc. Chem. Commun., 525-526. 
8. Kamo, T., Hirai, N., Tsuda, M., Fujioka, D., Ohigashi, H. 2000. Changes in the content and biosynthesis of phytoalexins in banana fruit. Biosci. Biotechnol. Biochem. 64, 2089-2098.

9. Schneider, B., Gershenzon, J., Graser, G., Schmitt, B., Hölscher, D., 2003. One-dimensional ${ }^{13} \mathrm{C}$ NMR and HPLC- ${ }^{1} \mathrm{H}$ NMR techniques for observing carbon-13 and deuterium labeling in biosynthetic studies. Phytochemistry Rev. 2, 31-43.

10. Hölscher, D., Schneider, B., 2005. The biosynthesis of 8-phenylphenalenones from Eichhornia crassipes involves a putative aryl migration step. Phytochemistry 66, 59-64.

11. Schneider, B., 2007. Nuclear magnetic resonance spectroscopy in biosynthetic studies. Progr. Nucl. Magn. Reson. Spectrosc. 51, 155-198.

12. Kawai, S., Nakata, K., Ohashi, M., Nishida, T., 2008. Myricanol and myricanone biosynthesis in Myrica rubra: incorporation of two molecules of 4-coumaric acid. J. Wood. Sci. 54, 256-260.

13. Fritzemeier, K. -H., Kindl, H., 1983. 9,10-Dihydrophenanthrenes as phytoalexins of orchidaceae. Biosynthetic studies in vitro and in vivo proving the route from L-phenylalanine to dihydro-m-coumaric acid, dihydrostilbene and dihydrophenanthrenes. Eur. J. Biochem. 133, 545-550.

14. Reinecke, T., Kindl, H., 1994. Characterization of bibenzyl synthase catalysing the biosynthesis of phytoalexins of orchids. Phytochemistry 35 , 63-66.

15. Schmitt, B., Schneider, B., 2001. Phenylpropanoid interconversion in Anigozanthos preissii observed by high-performance liquid chromatography-nuclear magnetic resonance spectroscopy. Phytochem. Anal., 12, 43-47. 
16. Schröder, J., 1997. A family of plant-specific polyketide synthase: facts and predictions. Trends Plant Sci. 2, 373-378.

17. Brand, S., Hölscher, D., Schierhorn, A., Svatos, A., Schröder, J., Schneider, B., 2006. A type III polyketide synthase from Wachendorfia thyrsiflora and its role in diarylheptanoid and phenylphenalenone biosynthesis. Planta 224, 413-428.

18. Ramirez-Ahumada, M. del C., Timmermann, B. N., Gang, D. R., 2006. Biosynthesis of curcuminoids and gingerols in turmeric (Curcuma longa) and ginger (Zingiber officinale): Identification of curcuminod synthase and hydroxycinnammoyl-CoA thioesterases. Phytochemistry 67, 2017-2029.

19. Katsuyama, Y., Matsuzawa, M., Funa, N., Horinouchi, S., 2007. In vitro synthesis of curcuminoids by type III polyketide synthase from Oryza sativa. J. Biol. Chem. 282, 37702-37709. 
Figure legends

Fig. 1. Chemcial structures of ${ }^{13} \mathrm{C}$-labeled precursors. $\left(\cdot{ }^{13} \mathrm{C}\right)$

Fig. 2. Mass chromatograms of molecular ion regions of myricanol (I) and myricanone (II) using DI-MS with SIM mode.

A, D: unlabeled, $\boldsymbol{B}, \boldsymbol{E}$ : formed after 3-(4-hydroxyphenyl)- $\left[1-{ }^{13} \mathrm{C}\right]$ propionic acid ([1- $\left.\left.{ }^{13} \mathbf{C}\right]-\mathbf{I V}\right)$ administration, $\boldsymbol{C}, \boldsymbol{F}$ : formed after

3-(4-hydroxyphenyl)- $\left[1-{ }^{13} \mathrm{C}\right]$ propionic acid $\left(\left[\mathbf{1 -}{ }^{13} \mathbf{C}\right]-\mathbf{I V}\right)$ and $4-\left[8,9-{ }^{13} \mathrm{C}_{2}\right]$ coumaric acid $\left(\left[\mathbf{8 , 9 -}{ }^{13} \mathbf{C}_{2}\right]-\right.$ III) administration.

Fig. 3. ${ }^{13} \mathrm{C}-\mathrm{NMR}$ spectra of myricanol (I).

A: unlabeled, B: formed after 3-(4-hydroxyphenyl)- $\left[1-{ }^{13} \mathrm{C}\right]$ propionic acid ([1- $\left.\left.{ }^{13} \mathbf{C}\right]-\mathbf{I V}\right)$ administration, $C$ : formed after

3-(4-hydroxyphenyl)- $\left[1-{ }^{13} \mathrm{C}\right]$ propionic acid $\left(\left[\mathbf{1 -}{ }^{13} \mathrm{C}\right]-\mathbf{I V}\right)$ and $4-\left[8,9-{ }^{13} \mathrm{C}_{2}\right]$ coumaric acid $\left(\left[\mathbf{8 , 9 -}{ }^{13} \mathbf{C}_{2}\right]-\right.$ III $)$ administration.

Fig. 4. Detailed resonances of side-chain carbons in ${ }^{13} \mathrm{C}-\mathrm{NMR}$ spectra of myricanol (I).

A: unlabeled, B: formed after 3-(4-hydroxyphenyl)- $\left[1-{ }^{13} \mathrm{C}\right]$ propionic acid $\left(\left[\mathbf{1}^{\mathbf{1 3}} \mathbf{C}\right]-\mathbf{I V}\right)$ administration, $C$ : formed after

3-(4-hydroxyphenyl)- $\left[1-{ }^{13} \mathrm{C}\right]$ propionic acid $\left(\left[\mathbf{1 -}{ }^{\mathbf{1 3}} \mathrm{C}\right]-\mathbf{I V}\right)$ and $4-\left[8,9-{ }^{13} \mathrm{C}_{2}\right]$ coumaric acid ([8,9- $\left.\left.{ }^{13} \mathbf{C}_{2}\right]-\mathbf{I I I}\right)$ administration (0:signals derived from $\left[\mathbf{1}-{ }^{\mathbf{1 3}} \mathbf{C}\right]-\mathbf{I V}$, signals derived from $\left[8,9-{ }^{13} \mathbf{C}_{2}\right]-$ III). 
Fig. 5. Proposed biosynthetic pathways for myricanol (I) from 4-coumaric acid (III) in M. rubra. 
Table 1. Mass spectral data of molecular-ion region of myricanol (I) and myricanone (II) isolated from M. rubra

\begin{tabular}{|c|c|c|c|c|c|c|c|}
\hline \multicolumn{4}{|c|}{ Myricanol (I) } & \multicolumn{4}{|c|}{ Myricanone (II) } \\
\hline \multirow[b]{3}{*}{$m / z$} & \multicolumn{3}{|c|}{ Relative intensity (\%) } & \multirow[b]{3}{*}{$m / z$} & \multicolumn{3}{|c|}{ Relative intensity (\%) } \\
\hline & \multirow[b]{2}{*}{ Unlabeled } & \multicolumn{2}{|c|}{ Isolated after administration of } & & \multirow[b]{2}{*}{ Unlabeled } & \multicolumn{2}{|c|}{ Isolated after administration of } \\
\hline & & {$\left[1-{ }^{13} \mathrm{C}\right]-\mathrm{IV}$} & $\begin{array}{c}{\left[8,9-{ }^{13} \mathrm{C}_{2}\right]-\text { III \& }} \\
{\left[1-{ }^{13} \mathrm{C}\right]-\mathrm{IV}}\end{array}$ & & & {$\left[1-{ }^{13} \mathrm{C}\right]-\mathrm{IV}$} & $\begin{array}{c}{\left[8,9-{ }^{13} \mathrm{C}_{2}\right]-\mathrm{III} \&} \\
{\left[1-{ }^{13} \mathrm{C}\right]-\mathrm{IV}}\end{array}$ \\
\hline 358 & 100 & 100 & 100 & 356 & 100 & 100 & 100 \\
\hline 359 & 23.1 & 25.3 & 24.9 & 357 & 23.8 & 26.0 & 26.5 \\
\hline 360 & 3.8 & 7.1 & 7.7 & 358 & 4.7 & 7.9 & 11.4 \\
\hline 361 & 0.5 & 1.5 & 2.5 & 359 & 0.9 & 1.5 & 5.1 \\
\hline 362 & 0.1 & 0.5 & 1.4 & 360 & 0.4 & 0.4 & 3.1 \\
\hline
\end{tabular}


Table 2. Relative absorption intensities of heptane-chain carbons signal based on the intensity of C-10 in ${ }^{13} \mathrm{C}-\mathrm{NMR}$ of myricanol (1) isolated from $M$. rubra

\begin{tabular}{|c|c|c|c|}
\hline & \multirow{2}{*}{ Unlabeled } & \multicolumn{2}{|c|}{ Isolated after administration of } \\
\hline & & {$\left[1-{ }^{13} \mathrm{C}\right]-\mathrm{IV}$} & {$\left[8,9-{ }^{13} \mathrm{C}_{2}\right]-\mathrm{III} \&\left[1{ }^{13} \mathrm{C}\right]-\mathrm{IV}$} \\
\hline C-7 & 1.01 & 0.97 & 1.03 \\
\hline C-8 (doublet) & - & - & $1.67^{* 1}$ \\
\hline C-8 (singlet) & 0.95 & 0.90 & 1.11 \\
\hline C-9 (doublet) & - & - & $2.09^{* 1}$ \\
\hline C-9 (singlet) & 1.01 & 3.65 & 4.28 \\
\hline C-10 & 1.00 & 1.00 & 1.00 \\
\hline C-11 (doublet) & - & - & $0.46^{* 1}$ \\
\hline C-11 (singlet) & 1.11 & 3.58 & 4.98 \\
\hline C-12 (doublet) & - & - & $0.55^{* 1}$ \\
\hline C-12 (singlet) & 0.86 & 0.82 & 1.08 \\
\hline C-13 & 0.95 & 1.03 & 1.07 \\
\hline
\end{tabular}

${ }^{* 1}$ sum of doublet intensities 


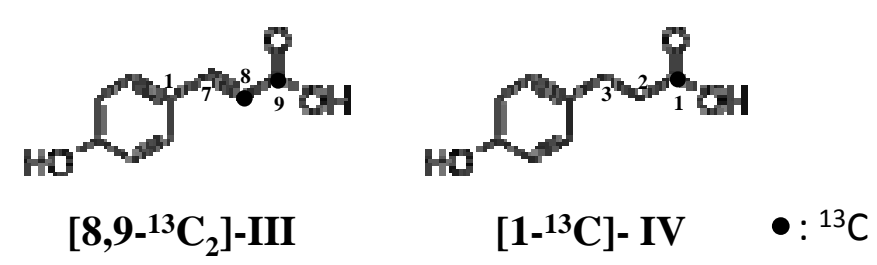

Fig. 1 Kawai et al. 

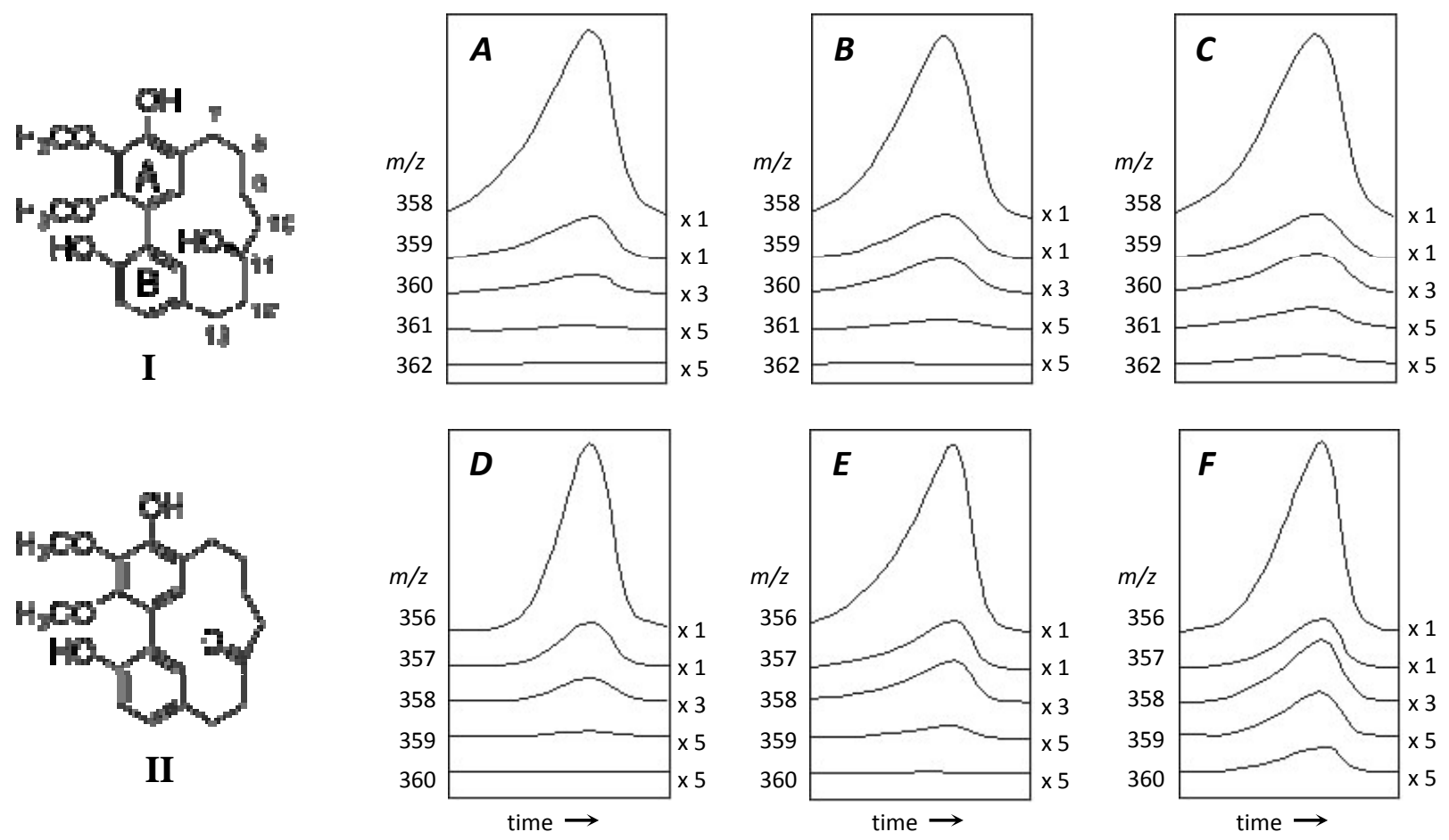

Fig. 2 Kawai et al. 

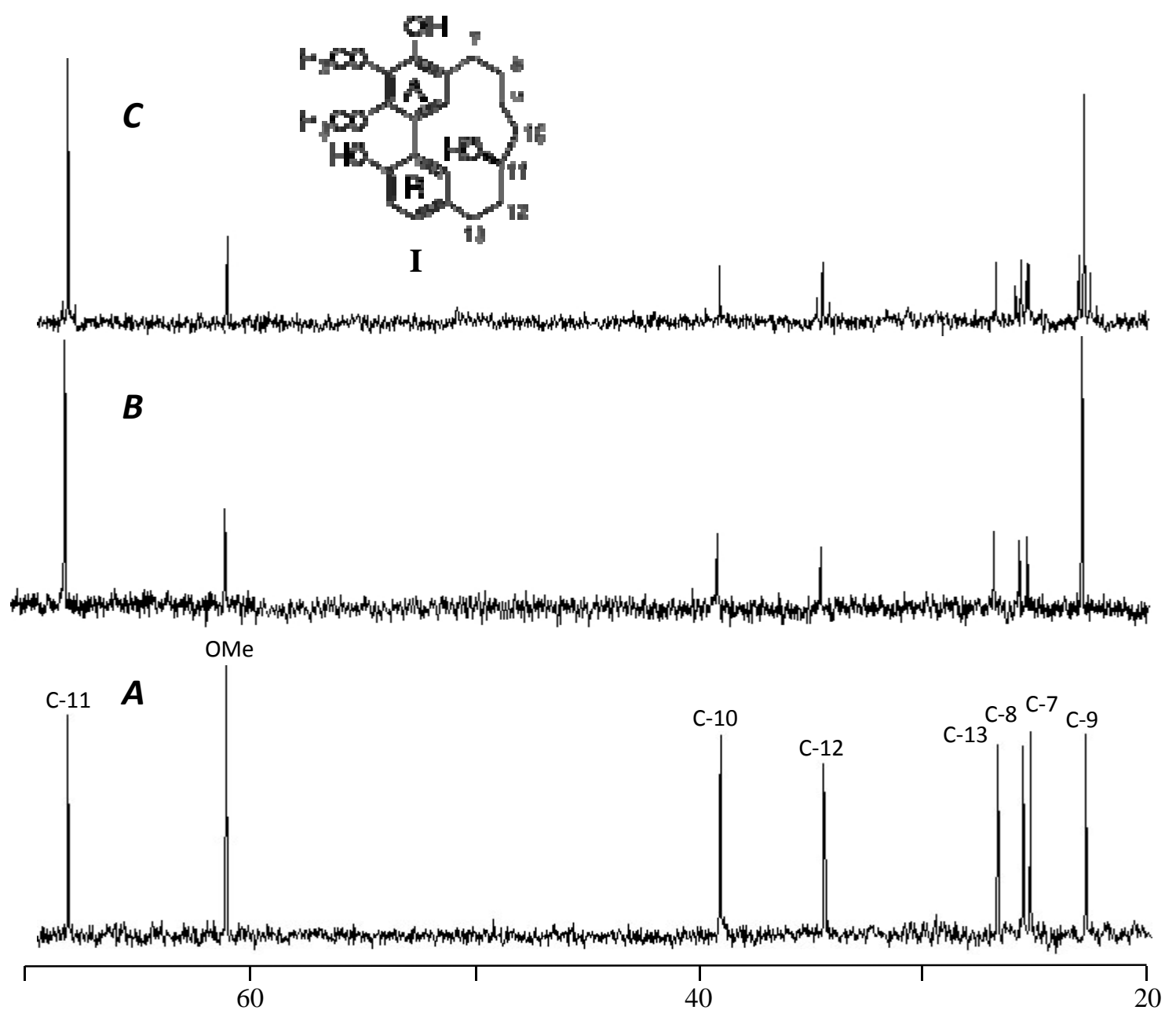

(ppm)

Fig. 3 Kawai et al. 


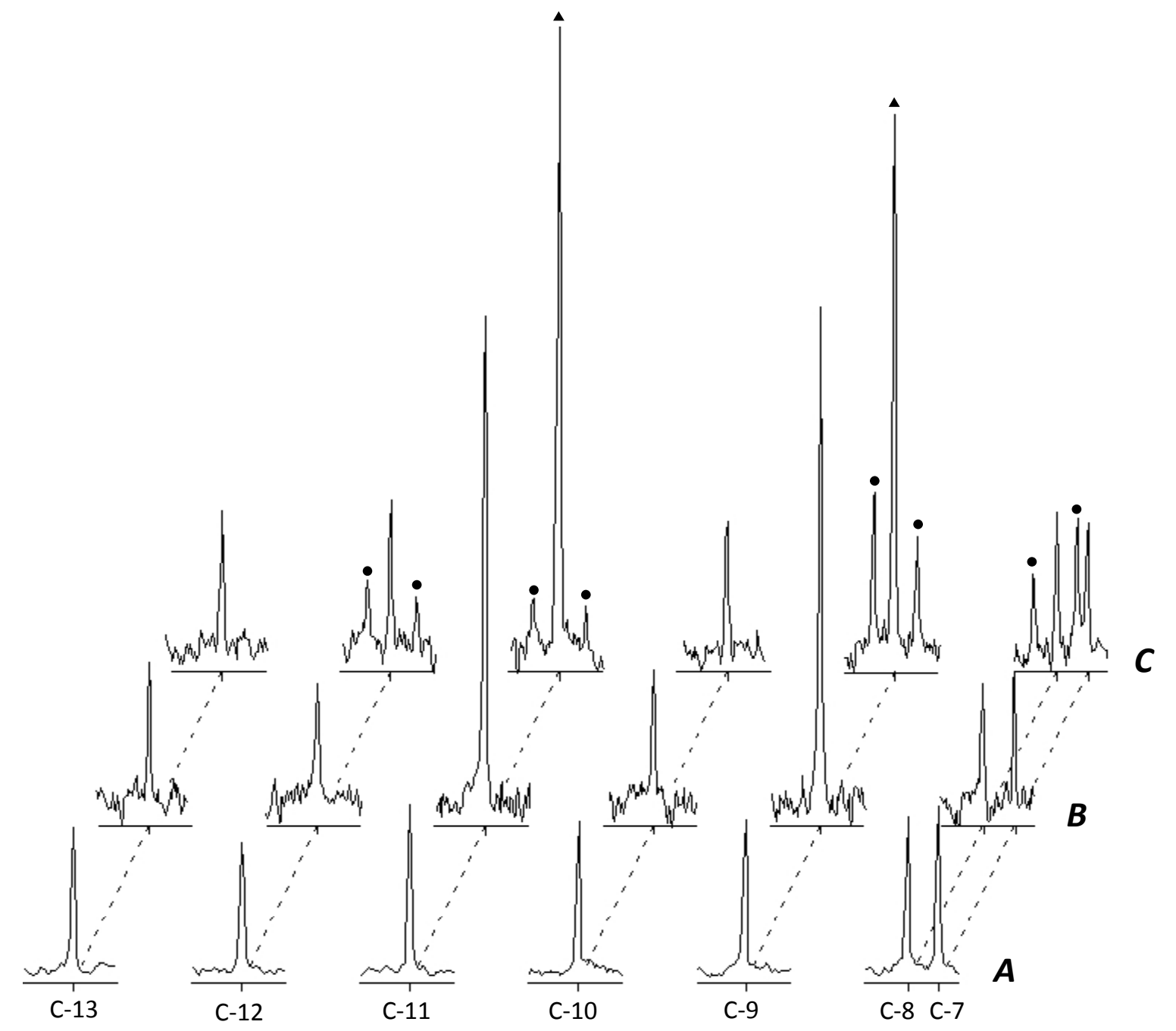

Fig. 4 Kawai et al. 


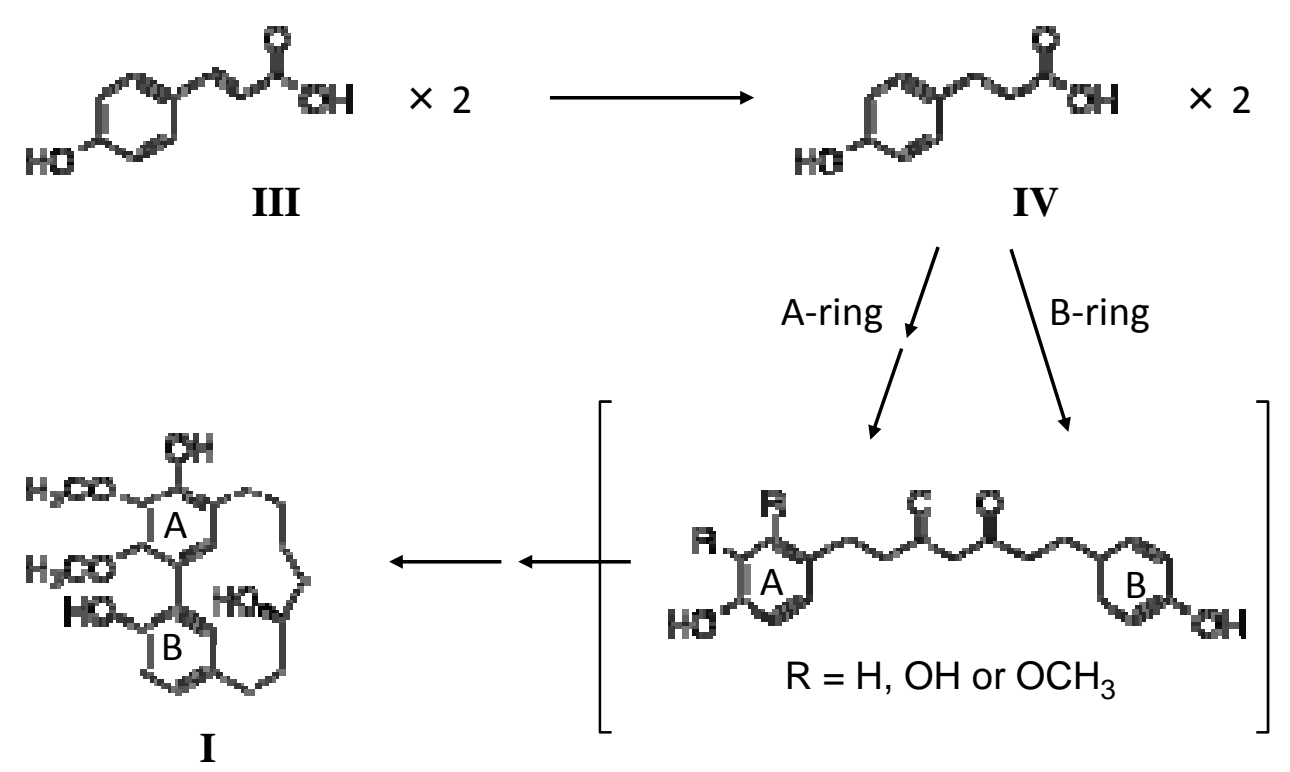

Fig. 5 Kawai et al. 